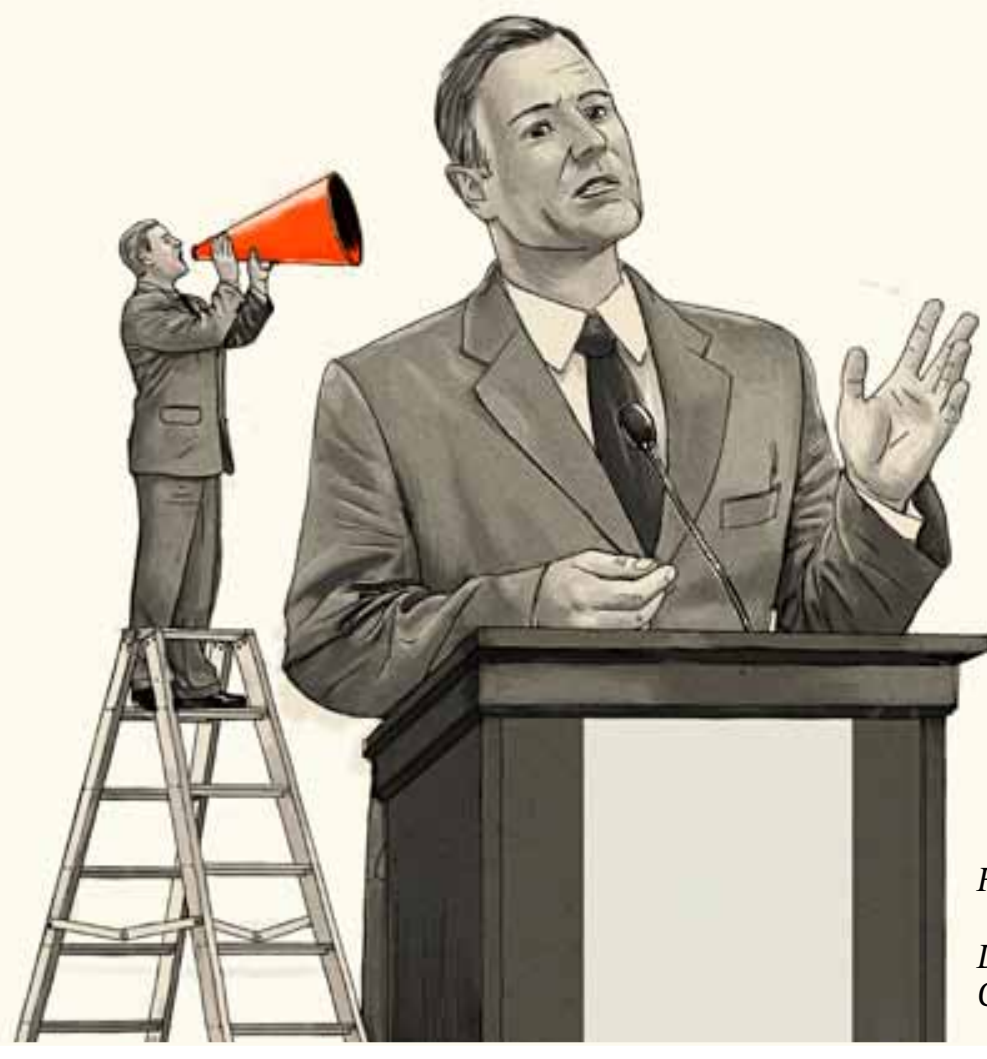

\section{LA GESTIÓN}

Se habla de la desconfianza de la ciudadanía en el gobierno politica y sus instituciones. La experiencia real y cotidiana de ejercicio de gobierno de toda persona se inicia en su espacio más próximo y vital, que generalmente es aquel administrado por e nistración de la salud, en la educación pública básica y secundaria en los servicios de aseo y mantención de espacios públicos, programas sociales, culturales, de recreación y deportes, etc. También, es Un actor normativo. a traves de ordenanzas en los planos reguladores, definiendo los niveles de participación, entre otros aspectos. Sin embargo, se hacen cotidianos los escándalos a nivel municpal en estas materias. Por ejemplo, a proposito de procesos de lictación de servicios de basura, el Consejo de Defensa del Estado se querello contra los alcaldes de Maipú y Cerro Navia, además de varios concejales, por cohecho, soborno y lavado de activos. Los mucionados por mal uso de recussos municipales a financiar costosos "viajes de estudio y capacitación" para sus concejales que superan los cien millones anuales. En el municipio de Zapallar se cruzan denuncias entre el alcalde y funcionarios a propósito de licitaciones fraudulentas y honorarios pagados por servicios no prestados a "palos blancos". En la municipalidad de Quinta Normal se querell el Consejo de Defensa del Estado contra la alcaldesa por malversación de caudales públicos puesto que no son habidos 700 millones que debian ser destinados al Programa de Integración Escolar. En La Pintana existen denunclas por la contratacion de fubolistas para equipo Deportes La Pintana, a través de recursos de la Subvención Escolar Preferencial (SEP), en el que aparecen los deportistas en cargos $y$ funciones que nunca ejercieron

Con todo esto, no sorprende que sean las múnicialidades las de equipamiento, material didáctico, mantenimiento de edificacio-

4) Salud 13\% (remuneraciones de personal del Departamento
MUNICIPAL

TAMBIÉN ES LA GESTIÓN DEL ESTADO

Por Eduardo Abarzúa C.

Director del Magister en Gestión de Personas. Ph.D en Ciencias del Trabajo. U. Católica de Lovaina.

en los últimos tres años. (Encuesta Nacional de Corrupción 2015 (O) rica, por el propósito de la corrupción, demasiadas respuestas están alineadas con las facultades de un municipio ganar una licitación acelerar un trámite, entregar un permiso e influir una regulación. Y la corrupción no tiene color politico, según la Unidad Especializada Anticorrupción de la Fiscalia, los casos son transversales e incluso

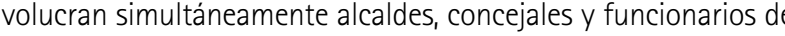
Clistintas coaliciones.

Las municipalitades por ley gozan de autonomia financiera patrmonial, por lo que están más expuestas a casos de corrup-

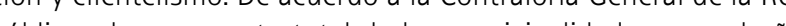
pe15 fue de $\$ 606$ bllotal de las municipalidades para el año $94 \%$ de sus gastos:

1) Gestión intor: 3 a (opercin de los servios par b gestión municipal, por ejemplo sueldos);

2) Educacín $27 \%$ (remunerciones de personal del Departamento de los establecimientos dependientes, además se destinan recursos a pago de servicios básicos de las escuelas o liceos, compra nes, entre otros):

3) Servicios a la comunidad: $20 \%$ (funcionamiento y mantención de los bienes y servicios de uso público tales como, servicios de aseo y ornato de espacios públicos, extracción de basura, electricidad para el alumbrado público, agua, entre otros: de los establecimientos dependientes, además incluye el pago de servicios básicos de postas o centros de salud, compra de equipadificaciones, entre otros).
Diversos estudios demuestran que la mayoría de los actos de corrupción se generan al interior los municipios, involucrando segú Afredo Rehren a algunos componentes de las triada alcalde-consejo municipal, burocracia local o funcionarios municipales y la comunidad local o grupos de interés (Alfredo Rehren B., "Corrupción y

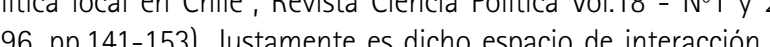
1996, pp.141-153). Justamente es dicho espacio de interacción y alta autonomia el que debe ser revestido con los mejores antidotos personas capacitadas e información a la ciudadania.

1. Mejorar el control y la fiscalización especialmente en materia de compras y contratación de servicios

Como se hac dicho, uno de los factores de riesgo de corrupción ave manejan una gran cantidad de recursos dadas los difcaldes funciones que cumple el municipio. Más allá del control que pueda ejercer la ciudadanía, los dos órganos de control sobre la gestión del alcalde son el Consejo Municipal y la Contraloría General de la República.

internacional es traspasarles recursos que destinen, cada vez con .

Por lo mismo, los municipios como organización, deben adoptar yelicad de servicio a la comunidad. Disponiendo de sistemas de y yla rendición de cuentas, en el marco de una estructura organizacios a a cum dos prefesionalizada y mentocratica, hando estándaes adecuados de cumplimiento sobre ejecución presupuestaria Consisción financiera.

Consistentemente, el municipio no puede quedarse exento de os prespir. Hoy el alcalde puede, con altos grados de chiscracioalidad, cargar a programas el pago de honorarios Y s si bien se han caracterizado en la planta municipal cargos críticos de segundo nivel jerárquico, por ejemplo el Director de Obras, muchas funciones no se desarrollan en la práctica. Al mismo tiempo, los mecanismos de selección se omiten de las practicas vigentes en resto del Estado, donde la regla es la Alta Dirección Pública, en la que prevalecen criterios como la antigüedad en vez de las competencias profesionales.

dicho control es muy poco efectivo. El Consejo no tiene capacidades para ejercer una fiscalización efectiva (tiempo, recursos, etc.) peor aún, en varios de los casos de corrupción aparece involucrado con la autoridad comunal. Por lo mismo, deberia ser prohibida toda practica de cooptación como la contratación cruzada con otros municipios de concejales o sus allegados y las prebendas como pueden ser vistos los vijo

visitas internacionales. go de producidos los actos administrativos, siendo necesario -más bo de - codroles especificos en áreas sensibles Por ejemplo, las Corporaciones que han sido creadas por los municipios para gestion los fondos provenientes de los ingresos municipales y subvenciones, manejan los servicios más sensibles y con mayores ingresos salud, educación, cultura y medio ambiente, incluso en algunos casos tienen a cargo cementerios y la atención de niños y adultos mayores. Se trata de estructuras paralelas, dependientes del alcalde que muchas veces administran más recursos y personal que municipio, buscando disponer de mayor flexibilidad y agilidad en gestion. Asi sus adquisiciones no necesitan pasar por el portal Chile Compra, tampoco los sueldos de sus integrantes quedan sujetos las "rigideces" del escalafón administrativo. Por lo mismo, las Corporaciones no pueden quedar ajenas a fiscalización y control por parte de la Contraloria y deben estar sujetas a los mismos sistemas de rendición de
nes del Estado.

Otra medida que permite un mayor control es el uso como norma del portal ChileCompra facilitando la imparcialidad y publicida des procesos de asignación de recursos municipales. Del mismo modo se debería limitar la práctica de parcelar contratos que permiten la asignación directa.

2. Modernización de la gestión municipal y profesionalización de los cargos directivos

3. Transparencia y rendición de cuentas

Los municipios, según el Consejo para la Transparencia, Chile ransparente y la Fundación ProAcceso, son la institución que más pacidad presenta, siendo las principales falencias la información pe actos con terceros (concesiones, contra, las, permisos) y bación tención a mecanismos de participación. Dada las particularidades los municipios una solución que estas instituciones propon de información

Por ejemplo, la publicación de los contratos en las áreas de gastos y contratación de servicios más significativas: concesión de basura (y todos sus adendas), de mantención de áreas verdes, tc. Debe ser obligatoria la Declaración Patrimonial e Intereses

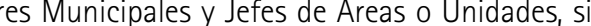
fusideración que sean o no jefes de departamento, sino de fusión que desempeñen. También hacer realmente accesible a municipales.

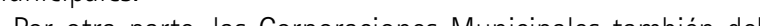
Por otra parte, las Corporaciones Municipales tambien debeción Pública Se neces de transparencia y Acceso a la Informaintos y de quienes participan en las ellas. También publicar los gestos

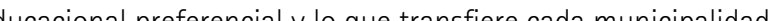
educación, como los gastos mensules en la materia Asimismo, debiera existir información respecto de contrataciones que realiza su personal administrativo, las funciones que desempeñan y remuneraciones que perciben

Como se ve, se habla de modernización del Estado olvidando que las municipalidades son el Estado a nivel local. Alli se imple-

Los municipios son la instancia de servicio público más cercana mentan las políticas públicas y, por lo mismo, se necesita control los ciudadanos, es el territorio de la descentralización. La tendencia capacidad de gestion, profesionalización y transparencia. 17 